\title{
A system dynamic approach for exploring the effects of climate change risks on firms' economic performance
}

\author{
I. Nikolaou ${ }^{\mathrm{a}}$, K. Evangelinos ${ }^{\mathrm{b}}$, W. Leal Filho ${ }^{\mathrm{c}, *}$ \\ ${ }^{a}$ Department of Environmental Engineering, Democritus University of Thrace, Vas Sofias 12, Xanthi 67100, Greece ${ }^{b}$ Department of Environment, \\ University of the Aegean, University Hill, Lesvos 81-100, Greece ${ }^{\mathrm{c}}$ School of Science and the Environment, Faculty of Science and Engineering, \\ Manchester Metropolitan University, Manchester, UK
}

\begin{abstract}
A number of studies have recently examined the potential relationships between climate change and the business community. The majority of such studies have emphasized statistical and benchmarking techniques to identify how climate change could have implications on firms' operations and their economic performance. These techniques draw primary data from questionnaire surveys and corporate environmental reports in an ex post basis, a fact that provide evidence in a linear, probabilistic and static character. These studies have provided limited insights regarding the future complex effects of climate change on corporate economic performance. This paper aims to contribute to this literature by developing a dynamic model to investigate the evolutionary trends of the relationships between climate change risks, financial performance and the operational processes of

firms. The main scope is to identify how physical, regulatory, reputational and litigation risks will affect day-to-day operations. An integrated model will be established in order to improve managers' and academics' understanding of climate change and business performance. Four scenarios will also be tested to illustrate "what if" relationships in the presence of climate change risks. Finally, the proposed model is based on the corporate climate change management, system thinking, system dynamic and Stella software.
\end{abstract}

Keywords:

Climate change risks

Corporate sustainability

System thinking

System dynamic

Stella software

\begin{abstract}
1. Introduction
Climate change is one of the most urgent threats to modern societies with direct and indirect consequences (e.g. extreme weather events and a strict institutional regime) to the steady growth of global economies (Stern, 2008). A number of scholars suggest adaptation strategies to protect cities from climate change impacts. The severity of climate change impacts on business operations differs according to the economic sector to which the firm belongs, examples being the tourist and leisure industry and the agricultural sector. The shortening of ski seasons and the inability of agribusiness to produce specific agricultural products are some significant results of climate change. Scott and McBoyle (2007) identified that ski operators and their investors have recently realized the growing vulnerability of their operations to the negative effects of climate change and the higher costs of mitigation and adaptation strategies which are undertaken by firms to respond to these problems. Similarly, many adaptation options have been.
\end{abstract}

fines paid by firms due to an inability or reluctance to comply with the requirements of climate change public policy.

The aforementioned risks emerging from climate change are likely to drive some firms to create new innovations and gain benefits. Pinkse and Kolk (2010) identified that many innovations have been created by various firms, mainly large, in their attempt to respond to climate change policy such as technological innovations, complementary capabilities and socio-technical innovations. Considered it vital for a firm's viability to incorporate the potential risks of an extreme weather event into their strategic management in an attempt to exploit some innovative resources and capabilities and reduce the risk of possible organizational collapses.

This paper aims to develop a system dynamic model to improve the understanding of academics and managers regarding the impact of climate change on business operations. The proposed model highlights the influences of undertaken by the agricultural sector to relieve climate change impacts such as technological developments, governmental and insurance programs and production and financial management techniques (Smit and Skineer, 2002).

The impacts of climate change are considered a potential financial risk for a number of industrial sectors. Some international organizations have classified climate change risks into the following categories: physical risks, regulatory risks, reputation risks and litigation risks (CERES, 2010). Depending on the sector and the frequency of the physical risks (e.g. droughts and floods), a series of consequences on the operations and production processes have been identified including an irregular supply of raw materials (supply chain risks), the relocation of their business units and interruptions to transportation. Proposed resilience thinking in order for firms to cope with physical risks. Regulatory risks are mainly associated with the types of mitigation and adaptation strategies which firms have undertaken to comply with the requirements of existing environmental legislation and regulations (Blyth et al.,

2007). Reputation risks refer to the negative image of some firms stemming from the use of outdated equipment resulting in high levels of environmental pollution, energy consumption and Green House Gas emissions (GHG). Litigation risks may result in heavy

climate change policy, stakeholders' perceptions (e.g. customers and investors) and of extreme weather events on business operations. The formation of the model is firstly based on some key propositions developed from the analysis of the current literature on corporate strategies and climate change. The proposed model was developed using the STELLA software program.

The rest of the paper includes five sections. The first section develops the methodology and the framework. The second section includes the analysis of the current literature on the potential effects of climate change on a company's operations. The third section provides a casual model diagram prepared using the STELLA software program. The next section tests some scenarios for the strategies undertaken by firms to avoid potential climate change risks and the final section analyzes the conclusions and discussion. 2. Methodology 
The proposed methodology is structured as follows a) the proposition development and b) the system dynamic structure. The first part is based on literature review and case study research in order to identify the key variables of the proposed model. Important information emerges in case studies since the empirical description of a specific topic is developed from various data sources (Yin, 1994). This approach assists the researcher in examining a topic in the real world and derives information to built a general theory. Eisenhardt and Grabner (2007) argued that data arising from case studies, and current literature are very important to built explicit propositions and theories. A sufficient number of cases range from 3 to 12 (Yin, 1994). This paper drew data from eight case studies carried out in the agribusiness and ski sectors. In particular, managers from agribusiness and the ski industry were questioned on their awareness of the risks of climate change on their firms' operations. Additional data was drawn from corporate climate change literature and similar academic reports. The decision to focus on these sectors is based on the higher threat which they face from climate change and the existence of significant scientific debate about these sectors. It is worth noting that the findings will improve the understanding of the potential climate change risks on other sectors.

The propositions are the base for identifying the key variable of the system and their feedback. Also, system dynamic thinking needs to use some particular examples for creating correct archetypes (stock and flow diagram and casual loop diagram)

(Wolstenholme, 2003).

Fig. 1 illustrates in detail the schematic representation of the proposed methodology. The first step outlines the main sources of data for identifying the variables and developing the propositions for their relationships. The next step provides the connection of case study research and system approach by developing a system dynamic model through proposition development. Three case studies were conducted in ski resorts in Greece and over twenty cases studies in the agribusiness in Northern Greece where climate change impacts are more significant through extreme floods and droughts. An interview protocol was developed with questions assessing the perception of respondents about the importance of parameters and their connections as they arisen from current literature. Additionally, a number of scenarios are tested to identify the sensitivity of some key variables to the overall system.

\section{Propositions development}

Academics have examined how climate change might lead to costs and benefits to the business community and general economy (Levy, 1997; Tol, 2002). A number of potential positive and negative impacts on firms have been examined by the literature such as the possible financial costs, production and operation risks, the concern of stakeholders for business viability and the increase of the market share and the creation of new innovations. Two streams of thought can be identified in the relevant literature analyzing business and environmental issues; the one from environmental economics and the other from corporate environmental management (Reinhardt, 1999). The former, considers environmental degradation as externalities which affect social welfare (Jaffe et al., 2005). The latter identifies that these externalities are the ground for generating new innovations and entrepreneurships (Cohen and Winn, 2007). According to environmental economics, climate change might cause a number of barriers for firms mainly due to the needs of further financial resources to moderate the consequences of the possible risks (e.g. extreme weather events) and to adapt their operations according to the contemporary requirements of climate change policy (e.g. legislation). Corporate Environmental management indicates that, under specific circumstances, the requirements for climate change adaptation and mitigation is likely to provide a competitive advantage to firms and new opportunities for profits. Following, the analysis is classified in two general sub-sections, the risks and the benefits for firms from climate change impacts.

\subsection{Climate change risks and benefits}

Climate change could entail a number of risks for firms. Academics and international organizations have classified these risks in a number of categories such as the physical risks, regulatory risks, reputation risks and litigation risks (CERES, 2010). Physical risks have many different consequences on firms' operations. Linnenluecke et al. (2011) presented an integrated framework to assist vulnerable sectors in incorporating relocation aspects into their strategic management in order to be prepared for the large scale impacts of climate change. They also supported that environmental quality is a significant external factor (among economic, social, political and technological) which play a critical role in the operation of firms. Scott and McBoyle (2007) argued that the ski industry is threatened by climate change such as less frequent snowfall and a shortened skiing season. Griffiths et al. (2007) provided useful evidence to facilitate firms to incorporate climate change strategies into the supply chain management. Literature indicates that floods and droughts might directly affect the production capabilities of agriculture and indirectly certain economic sectors such as the food industry, while extreme weather events may affect the transportation of raw materials and final products to global markets. The case studies that were examined provide similar findings. In particular, the managers who participated in the research consider that their future viability is considerably threatened by climate change. However, the effects of physical risks on firms operations might be subject to the different level of the vulnerability of the specific sector (Bleada and Shackley, 2008). For example, the agricultural sector faces different problems to those faced by the, ski industry and the chemical industry. Thus, the key propositions arising from the above analysis are:

P1. Physical risks will negatively affect firms according to the level of vulnerability of the sector in which they operate

P2. Physical risks will affect the operations of firms either directly (e.g. mitigation or adaptation strategy) or indirectly (e.g. financial costs from disruptions of operation.)

The second type of risk (regulatory risks) includes the financial costs of firms to invest in mitigating and adapting strategies in an effort to comply with the requirements of climate change policy. Climate change policy (following general environmental policy) can be classified in three categories:

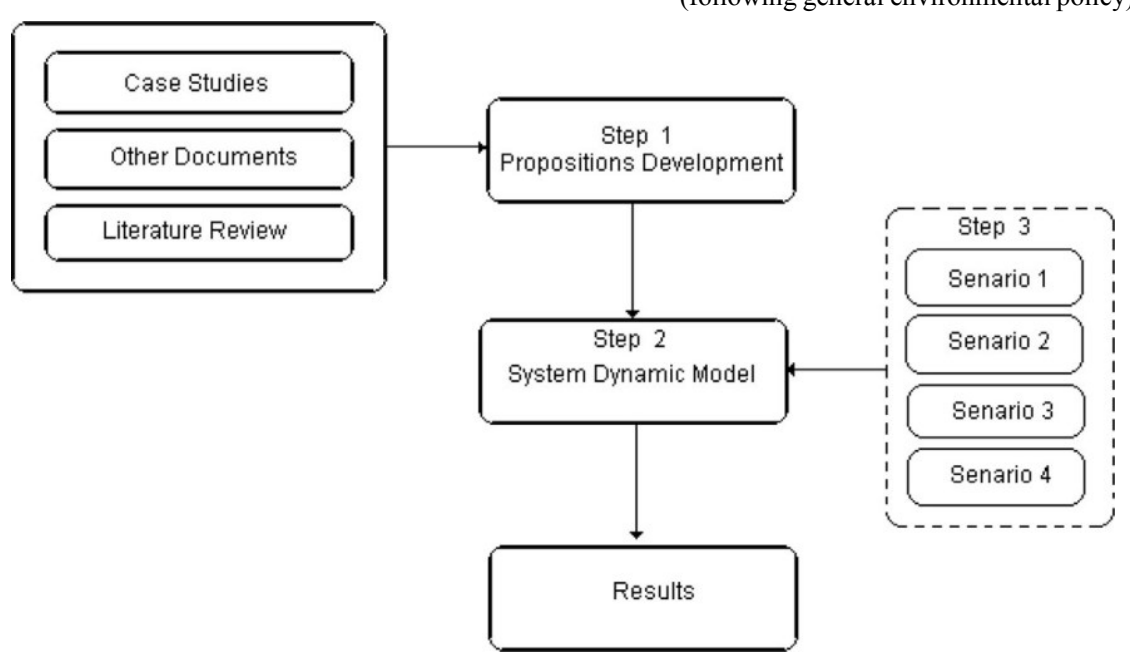


The first category includes 'command and control' policies (e.g. legislation) that compel firms to adopt strategies to respond to climate change (Reid and Toffel, 2009). The other category includes "market-based" policies (e.g. energy taxes, tradable permits) motivate firms to implement climate change strategies (Roughgarden and Schneider, 1999). The last category refers to voluntary instruments adopted by firms to cope with the challenges of climate change and gain economic benefits (Boiral, 2006). The first two categories are explained by the institutional theory where firms are motivated to adopt climate change strategies under an explicit institutional regime. The third category is explained either as the response of firms to various stakeholders in climate change topics or as a resource-based view of firm (Kolk and Pinkse, 2007). The interviews of the case study research indicate that managers consider that the "command and control" climate change tools would have the greatest impact on their decisions. They also rank market-based instruments in second. Finally, although the respondents have taken into account the views of stakeholders (e.g. customers) regarding environmental issues, they are not in the position to define certain benefits arisen from stakeholders from the adoption of environmental management strategies. The key propositions arising from the analysis above are:

P3. "Command and control" climate change policies will force firms to adopt climate change mitigation and adaptation strategies by increasing total costs.

P4. Market-based climate change policies might drive firms to adopt climate change mitigation and adaptation strategies by increasing total costs

P5. Stakeholders' interest in climate change topics might affect firms to adopt relevant strategies by increasing total costs

The third category of climate change risk includes reputation damages resulting from issues such as inadequate strategies on climate change performance and relevant accidents. Some business sectors are considered more responsible than others regarding climate change due to a lower carbon footprint (Ro€os et al., 2010€). There are business sectors which have been increasingly exposed to climate change risks threatening their reputation. Kolk and Pinkse (2007) argued that having a business strategy to respond to climate change is very important to positively affect public opinion, while the lack of any strategy might lead to the opposite. Arnell and Delaney (2006) considered that business adaptation strategies are mainly adopted in order to maintain their reputation. The respondents in the case studies claimed that not having a strategy for environmental protection is negatively perceived. They supported that the absence of climate change strategies by firms can impact on stakeholders which may face increased risks. For example, banking sector could be reluctant to lend money to vulnerable firms from climate change due to the increased associated risk and the potential difficulties to payback loans. Similarly, consumers could avoid purchasing products from firms or areas where there is high impact of climate change because the quality of the products is not assured. After analyzing reputational risk, a rational proposition is:

P6. The absence of climate change strategies might cause reputational risks for firms.

The final category of business climate change risk is litigation risks. This type of risk is caused in the case where firms have failed to meet legislative requirements and must pay the subsequent fines and penalties. These risks might lead to sudden expenses to firms' operations and create the need for additional financial resources. The respondents confirmed these findings by mentioning that noncompliance with environmental policies leads to fines. A rational proposition is:

P7. The non-compliance of firms with climate change policy requirements may result in additional and sudden costs.

Climate change policies are likely to encourage firms to adopt a number of adaptation and mitigation strategies in order to advance their overall climate change performance. Apart from a better environmental performance, climate change strategies can create innovations improve business reputation and decrease total costs (Berkhout et al., 2006). Additionally, some types of mitigation strategies such as the reduction of carbon footprint provides a clear signal to consumers who are willing to pay for lower carbon footprint products (Iribarren et al., 2010). The respondents to the case study research point out that climate change strategies should create innovation and eliminate operational and production costs. This analysis could illustrate some important propositions such as:

P8. Climate change mitigation and adaptation strategies should create innovations which decrease the total costs to firms.

P9. Climate change strategies may strengthen the willingness-to-pay of consumers that are sensitive to climate change rhetoric.

\section{Causal loop diagrams}

In this section, a casual model is presented based on the propositions developed in the previous section. Casual loop diagrams help in clarifying system operations and structure as they provide manageable representations of the key variables and their feedback (Sterman, 2000). Casual loop diagrams assist scholars to depict clearly and accurately the structure and the function of a system. It is also considered to be a simple means using stock and flows to represent the fundamental relationships of the key variables of a system. The variables used in casual loops are represented as modules and arrows which illustrate the key elements that could play a role in the behavior of a system as well as their feedbacks. The arrows are taking polarity signs (por) which illustrate the similar or dissimilar trajectories of the key elements. For example, the symbol $p$ indicates that two elements or variables simultaneously increase or decrease, while the symbol shows that when one increases the other decreases.

Fig. 2 illustrates the proposed casual loop which uses the aforementioned propositions. The proposed casual loop provides a number of key variables of the business system, climate change performance and climate change risks. This diagram aims to represent a common framework to clarify the necessary variables of business and climate change risks which could be modified according the needs of different business sectors in order to reflect the conditions in which they operate. Different colors have been selected to point out the key elements of the proposed model such as red (in web version) for economic performance and climate change performance, while green (in web version) represents the four types of climate change risks. The arrows signify the links between the key elements of the proposed casual loop.

Climate change risks are considered external factors that affect business operations. These risks are analyzed in order to increase the understanding regarding the feedback of elements and variables. The first type of climate change risk, physical risks, might have an effect on operations in two ways. The first way shows the limitations of firms to cope with the direct threats of an extreme weather event which is likely to increase both their vulnerability for future operations and total costs in order to absorb direct financial losses (as shown in proposition 1 e P1). The second way shows the gradual consequences of climate change that might be faced by firms through the adoption of certain mitigation and adaptation strategies which is directly associated with the degree of the vulnerability of the firms (as explained in proposition 2 e P2). Therefore, the degree of vulnerability varies according to the business sector (Jones and Levy, 2007; Kolk and Pinkse, 2007). The total costs could be eliminated when firms adopt mitigation and adaptation strategies since various technological and management innovations could be achieved. 
The second type of climate change risk (regulation risk e strict institutional regime) is highlighted in the casual loop diagram with the variable of climate change regulation risks and it is presented as an external variable that influences the decision of managers (as explained in propositions 3 and $4 \mathrm{e}$ P3, P4) to choose from various types of mitigation and adaptation strategies. The selection of firms of an essential strategy to respond to climate change risks is associated with their economic performance capability. Additionally, the successful implementation of the mitigation and adaptation strategies is likely to generate innovations (according to proposition 8 e P8) a fact that might decrease the total costs in the longrun. Additionally, the higher the mitigation and adaptation strategies undertaken by firms, the better climate change performance that could be achieved. The improved climate change performance is likely to be positively associated with the firms' reputation in the case where climate sensitive consumers and the financial sector require protection from climate change risks.

The third type of climate change risk is reputational risk which is examined by climate change reputation risks. This variable affects the reputation of firms as explained in proposition 6 (P6). A positive and negative reputation is likely to both affect the decision of consumers' and the financial sector's decisions. A positive reputation might encourage consumers to move towards firms with better climate change performance and therefore the revenues of such firms would increase, while a bad reputation as result of a climate reputation risks could negatively influence the demand of consumers. Similarly, a good reputation might positively influence the relation between the financial sector (e.g. investors, the banking sector and insurance companies) and the economic performance of firms since the financial sector has of late required a warranty for their investments. A bad name as result of climate change is likely to make the financial sector reluctant to invest in these firms.

The fourth type of risk is litigation risks. The low degree of compliance of firms with the requirements of environmental legislation could increase their costs due to the potential fines and penalties. Additionally, these fines might have a negative influence on firms' reputation and possibly (as mentioned above) on the decision of the financial sector to finance the general business

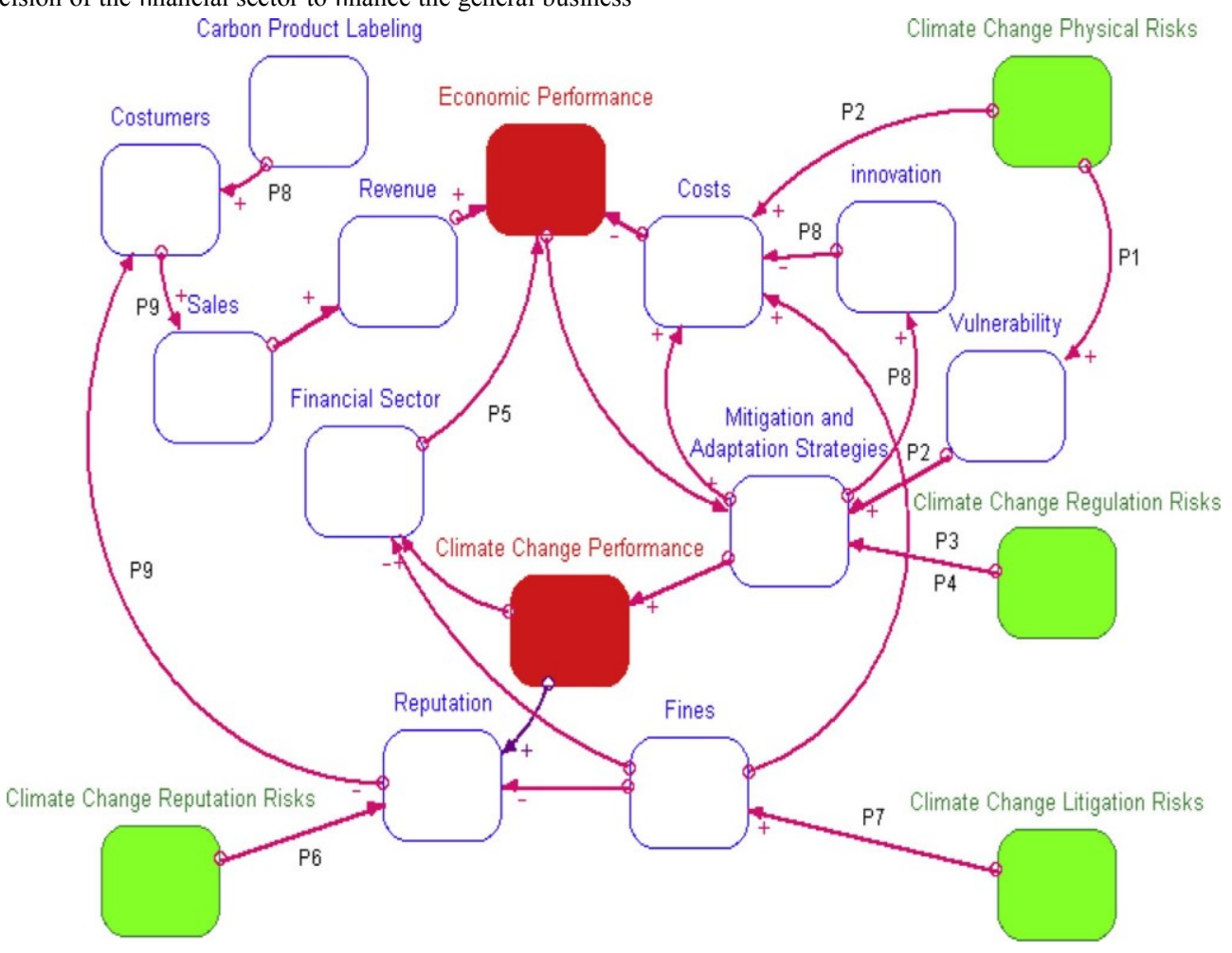

Fig. 2. A causal loop.

\section{A dynamic business model for climate change risks e scenario testing}

A simple system dynamic model has been developed using STELA software showing how climate change risks could affect, both positively and negatively, the economic performance of firms. This model aims to assist in the understanding of academics and managers for the "what if" scenarios for climate change risks.

The development of the model is based on the key elements of the casual loop diagram. Fig. 3 illustrates the key variables of the proposed model which have been organized in two main sets: the financial performance of firms (e.g. the corporate economic performance) and the effects of climate change on firms' operation (e.g. corporate climate change performance). Economists have examined the evolution of corporate profits under different market conditions (e.g. perfect competition, oligopoly and monopoly), demographic conditions (e.g. increase of population, the composition of population), macroeconomic conditions (e.g. inflation, and various levels of risk taken by managers (e.g. risk takers, risk neutral, and risk averse)). In the model, the variable corporate economic performance (e.g. profits) arises from the standard relationship of the revenue minus the costs as the classical economics and business literature show (p $1 / 4$ TR TC.)

plans of firms. 
The total revenue (TR) is calculated as the product of the price (P) and sales (Quantity). The total costs (TC) consists of the fixed costs

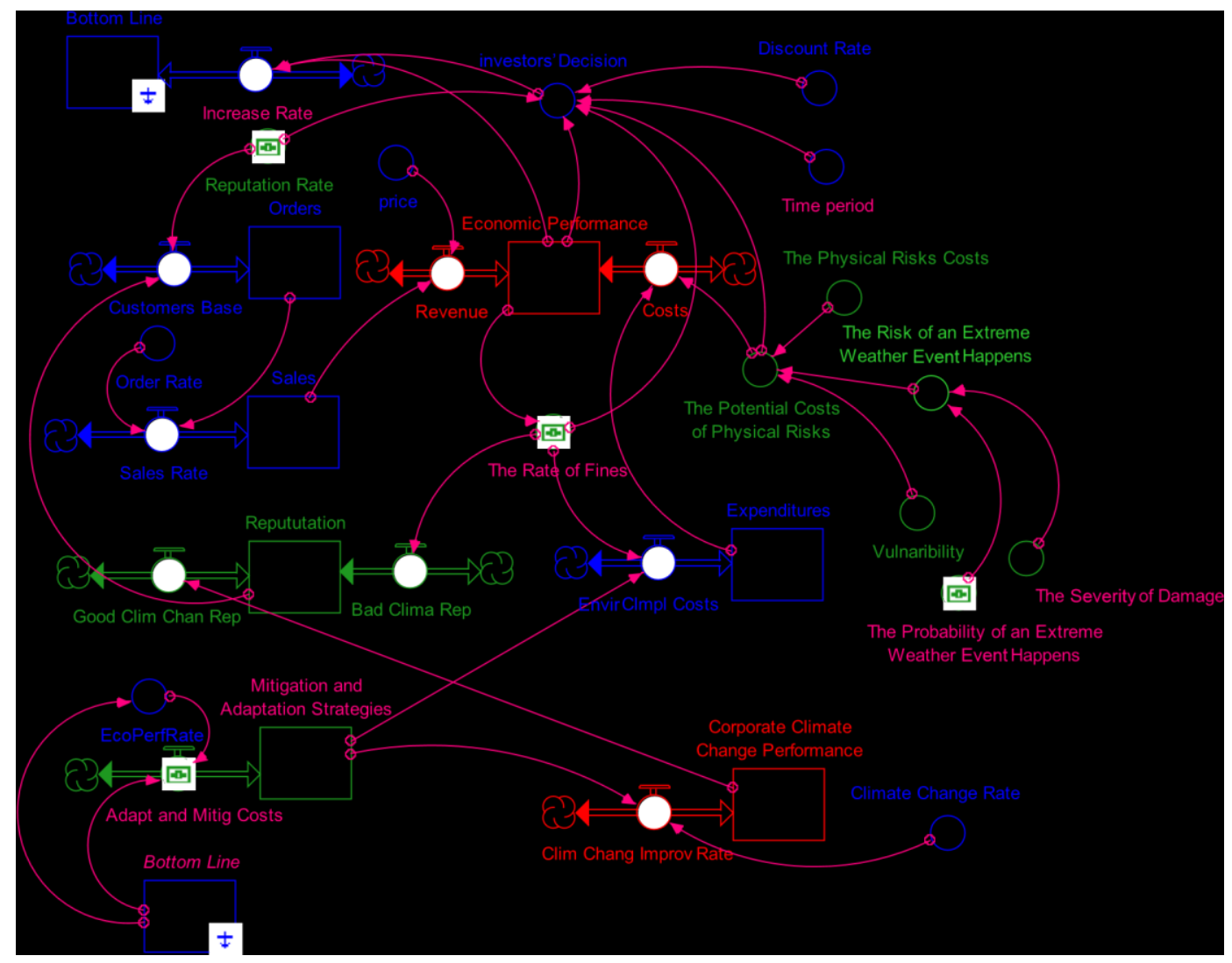

Fig. 3. The dynamic business climate change model. 
(FC) and the variable costs (VC). In the case of this model, the total cost includes the firms' expenditures for the climate change adaptation and mitigation strategies and rate of fines. The potential physical risks in the cases where firms have unexpected financial losses from an extreme weather event (e.g. droughts and floods) are also added to TC. The financial losses of physical risks are associated with the severity of the damage and the probability of an extreme events happening (Risk $1 / 4$ Damage*Probability). The expenditures of firms are also affected from the regulatory costs and the compliance costs of the mitigation and adaptation strategies. This type of cost could be the result of institutional requirements (as propositions 3 and 4 describe) or as a voluntary strategy to respond to the gradual worsening of natural conditions. It is hypothesized that only government policy affects the decision of firms to adopt strategies to respond to climate change. The financial capital for these strategies is arisen from the economic performance of firms as a constant part.

Under the hypotheses of the good management of firms, the adoption of climate change strategies affects their climate change performance such as the low carbon footprint of products. Jones and Levy (2007) claimed that large firms which have adopted green house gas (GHG) strategies have had limited effects on their carbon performance due to a weak institutional context and governmental control regime. A better climate change performance could positively affect firms' reputation and customers' preferences affecting sales and revenues. Chakrabarty and Wang (2013) showed that climate change mitigation strategies affect the reputation and the sales of firms. An improved reputation might also have a strong influence on the decision of the financial sector as illustrated in the casual loop diagram. Here, only the effect of investors' preference to invest in firms which achieve better climate change performance is examined. Some key variables that affect the investors' decision regarding climate change reputation are the potential costs of physical risks, the economic performance, and the rate of fines. It is calculated as the Net Present Value of economic performance added physical risks and the rate of fines for time period and discount rate (Blyth et al., 2007). The investors' decision affects the bottom line of firms and the economic performance of firms.

Following, some scenarios will be tested for each type of climate change risks.

\subsection{Physical climate change risk}

Fig. 4 illustrates that in the case of an extreme weather event the economic performance of firms may be affected and their climate change performance and the reputation can drop to zero. This implies that an extreme weather event has a direct effect on the total costs of firms due to a possible disruption in production and operations. Linnenluecke et al. (2012) provides a typology highlighting the impacts of extreme weather events on various sectors. They classified the events in three categories: simple extreme events with local impacts, complex extreme events with severe local impacts, and unique extreme events with global impacts. Here, the scenario is based on the first type and the impacts on agriculture and the ski sector (e.g. crop damage, decrease of tourist seasons).

The climate change performance of firms is close to zero as this scenario is based on the hypothesis that firms have not implemented any adaptation or mitigation strategies to respond to any potential extreme weather event. The absence of any strategy and the impacts of extreme weather events also explain the constant character of the reputation since firms constitute threatens for customers, suppliers and investors.

\subsection{Regulatory climate change risk}

The second scenario hypothesizes that firms have invested in mitigation and adaptation strategies as a response to climate public policy namely "command and control" instruments (e.g. legislation) and market-based instruments (e.g. energy taxes, tradable permits emissions). A choice of climate change strategies is available to firms to address climate public policy such as carbon footprint strategies, GHG technologies, tradable permits and ISO 14067. The adoption of climate change strategies means that the trajectories of economic performance, climate change performance and reputation will be positive under an effective management (Fig. 5). The adoption of the mitigation and adaptation strategies might lead to improvements in the climate change performance of firms. The improvement in environmental performance is likely to increase economic performance due to the enhancement of firms' reputation and provide a clear signal to customers who are willing to pay for low carbon footprint products.

\subsection{Reputation climate change risk}

The third scenario emphasizes the reputational risks of firms regarding climate change issues. The negative reputation of firms

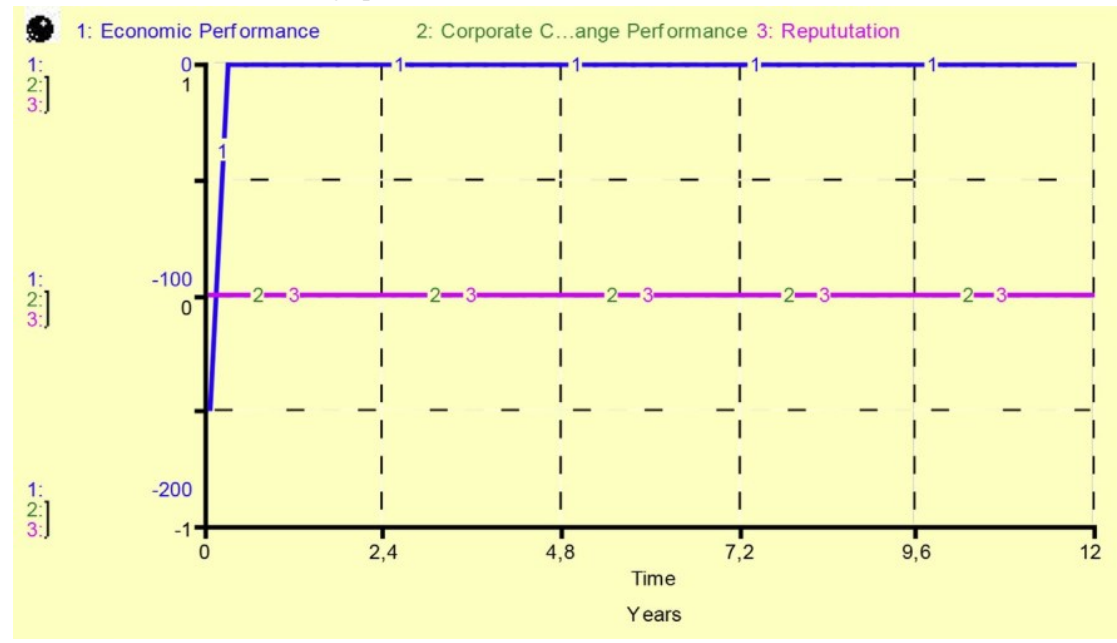

Fig. 4. The trends of key variables of the first scenario. 


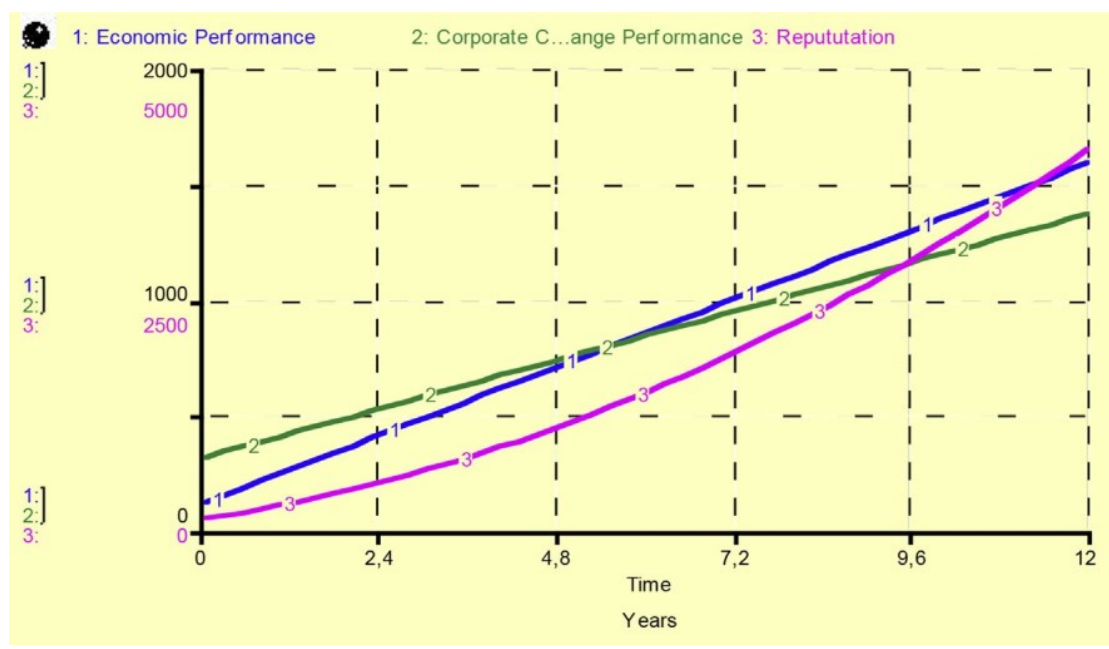

Fig. 5. The trends of key variables of the second scenario.

regarding climate change issues could affect their economic performance and their reputation. Skjærseth and Skodvin (2001) argued that a general demand for environmental quality is likely to encourage consumers towards environmentally friendly firms. They also pointed out that unexpected environmental accidents negatively affect the reputation of firms, the demand for their products, investors' decisions in relation to the firms and the views of suppliers. Fig. 6 illustrates that a negative reputation hold the economic performance and reputation unchanged, while leading firm to adopt strategies to improve their climate change performance.

\subsection{Litigation climate change risk}

The fourth scenario hypothesizes that firms pay a fine due to either noncompliance with the requirements of environmental legislation or from their impacts on the environment (externalities). Fig. 7 shows that after the fine, a slight displacement in the economic performance curve will take place, while the reputation and environmental performance of firms remain constant. This is explained since the firm's reputation and environmental performance would be affected by the non-compliance with climate change policy.

6. Discussion and conclusions
This paper develops a simulation model for examining the relationships between climate change risk and firms' operations. The dynamic model aims both to recognize the most vital variable of the complex system of firms and climate change impacts and to test a variety of scenarios in order to depict the potential evolution of a firm's operations. The proposed model assists in strengthening our understanding and offering a mental model to facilitate firms to design, according to their needs, an evolutionary strategy to avoid climate change risks. The methodology of this paper is based on system dynamic ideas and the propositions development through a case study research methodology.

The findings show that climate change physical risks are likely to have a strong effect on the economic performance of firms since they can increase the costs significantly. It is important to point out that these impacts vary between sectors (the degree of vulnerability) and can vary on the basis of the severity and the frequency of the physical risks. There are sectors which are unable to operate under current weather conditions (e.g. the ski industry) where the decreasing of the tourist seasons has negative effects on total revenues. The scenario here is based on the direct effect of extreme weather events on the costs of firms.

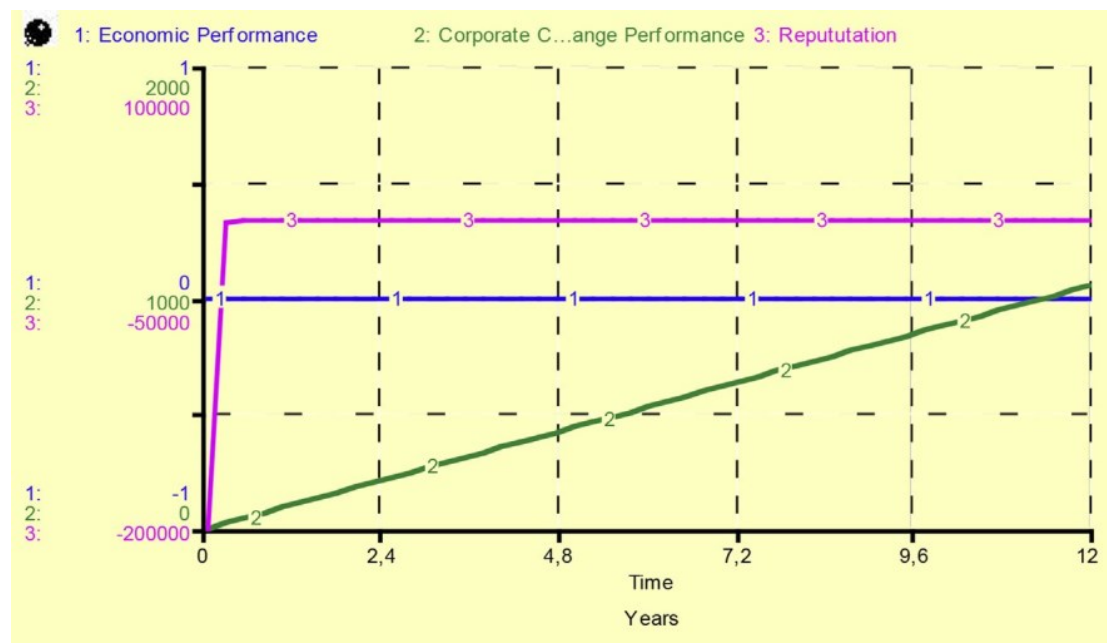

Fig. 6. The trends of the main variables in the third scenario. 


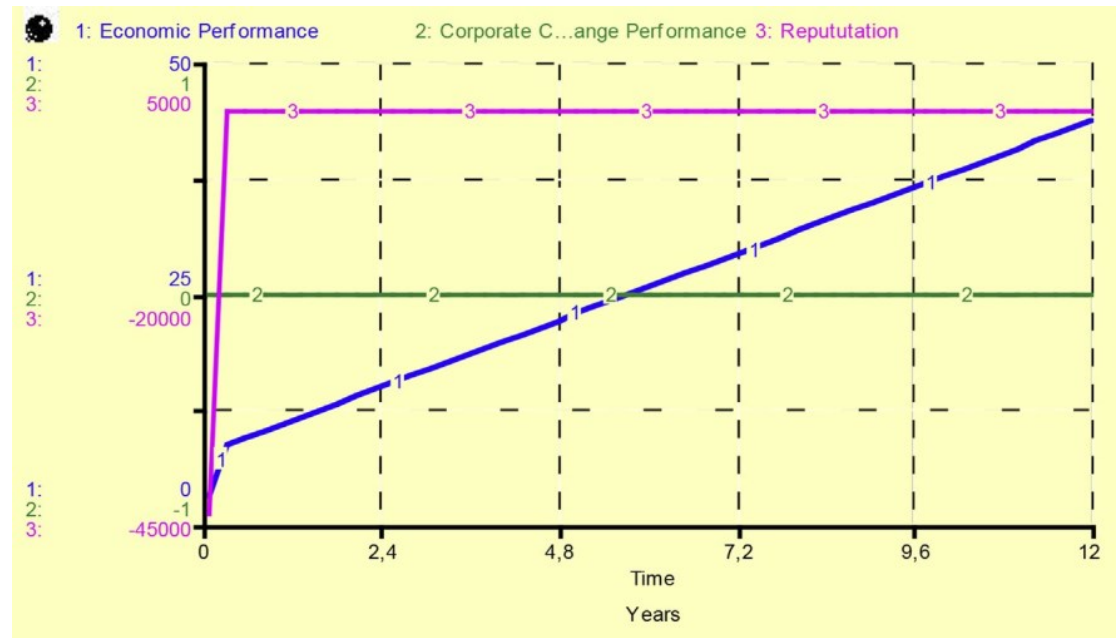

Fig. 7. The trends of key variables of the fourth scenario

In the case where the extreme weather events have a gradual influence on operations or climate change policy for firms then certain costs are identified. On the one hand, the findings indicate that firms which adopt (or are willing to adopt) strategies to respond to climate change issues or to climate change policy requirements are likely to increase their total costs. On the other hand, in those cases where these strategies are followed by innovations there may be positive effects on the reputation of firms to various stakeholders. This scenario, could be high-quality for firms which are pioneering (first mover view) to voluntarily implement climate change strategies seeing that they gain a competitive advantage over their competitors.

The other types of climate change risks including litigation and reputation risks could be associated with climate change policy or the inability of firms to achieve the goals of climate change policy. In particular, the model shows that litigation risks could lead to high fines which directly affect the economic performance of firms. However, the potential for liabilities make investors reluctant to invest in these firms. Similarly, reputational risks could arise due to the rapid increasing requirements of climate change policy (e.g. regulatory costs) and bad environmental performance.

The proposed methodology is a combination of system dynamics thinking and case study research assisting in the understanding of the relationship between climate change and firms' operation with the utilized data based both on subjective views and objective sources. It also assists in managing the progress of the overall system of firms' operation over a period of time. Finally this approach provides useful information regarding certain characteristics of the system such as the variables, feedbacks and stability.

\section{References}

Arnell, N.W., Delaney, E.K., 2006. Adapting to climate change: public water supply in England and Wales. Clim. Change 78, $227 \mathrm{e} 255$.

Berkhout, F., Hertin, J., Gann, D.M., 2006. Learning to adopt: organizational adaptation to climate change impacts. Clim. Change 78, 135e156.

Bleada, M., Shackley, S., 2008. The dynamics of belief in climate change and its risks in business organizations. Ecol. Econ. 517e532.

Blyth, W., Bradely, R., Bunn, D., Clarke, C., Wilson, T., Yang, M., 2007. Investment risks under uncertain climate change policy. Energy Policy 35, 5766e5773.

Boiral, O., 2006. Global warming: should companies adopt a proactive strategy? Long Range Plan. 39, 315e 330 .

CERES, 2010. Climate Change Risk Perception and Management: a Survey of Risk Managers. Coalitions for Environmentally Responsible Economies.

Chakrabarty, S., Wang, L., 2013. Climate change mitigation and internalization: the competitiveness of multinationals. Thunderbird Int. Bus. Rev. 55 (6), $673 \mathrm{e} 688$.

Cohen, B., Winn, M.I., 2007. Market imperfections, opportunity and sustainable entrepreneurship. J. Bus. Ventur. 22, 29e49.

Eisenhardt, K.M., Grabner, M.E., 2007. Theory building from cases: opportunities and challenges. Acad. Manag. J. 50 (1), $25 \mathrm{e} 32$.

Griffiths, A., Haigh, N., Rassias, J., 2007. A framework for understanding institutional governance systems and climate change: the case of Australia. Eur. Manag. J. 25 (6), 415 e427.
Iribarren, D., Hospido, A., Moreira, M.T., Feijoo, G., 2010. Carbon footprint of canned mussels form a business-to-consumer approach. A starting point for mussel processors and policy makers. Environ. Sci. Policy 13, 509e521.

Jaffe, A.B., Newell, R.G., Stavins, R.N., 2005. A tale of two market failures: technology and environmental policy. Ecol. Econ. 54, 167e174.

Jones, C.A., Levy, D.L., 2007. North American business strategies towards climate change. Eur Manag. J. 25 (6), 428e440.

Kolk, A., Pinkse, J., 2007. Multinationals' political activities on climate change. Bus. Soc. 46 (2), $201 \mathrm{e} 228$.

Levy, D.L., 1997. Business and international environmental treaties: ozone depletion and climate change. Calif. Manag. Rev. 39 (3), 54e71.

Linnenluecke, M.K., Griffiths, A., Winn, M., 2012. Extreme weather events and the critical importance of anticipatory adaptation and organizational resilience in responding to impacts. Bus. Strat. Environ. 21, 17e39.

Linnenluecke, M.K., Stathakis, A., Griffits, A., 2011. Firm relocation as adaptive response to climate change and weather extremes. Glob. Environ. Change 21, 123e133.

Pinkse, J., Kolk, A., 2010. Challenges and trade-offs in corporate innovation for climate change. Bus. Strat. Environ. 19, $261 \mathrm{e} 271$.

Reid, E.M., Toffel, M.W., 2009. Responding to public and private politics: corporate disclosure of climate change strategies. Strat. Manag. J. 30, 1157e1178.

Reinhardt, F., 1999. Market failure and the environmental policies of firms: economic rationales for "Beyond Compliance" behavior. J. Ind. Ecol. 3 (1), 9 e21.

Ro€o€s, E., Sunberg, C., Hansson, P.-A., 2010. Uncertainties in the carbon footprint of food products: a case study on table potatoes. Int. J. Life Cycle Assess. 15, 478e 488.

Roughgarden, T., Schneider, S.H., 1999. Climate change policy: quantifying uncertainties for damages and optimal carbon taxes. Energy Policy 27, 415e429.

Scott, D., McBoyle, G., 2007. Climate change adaptation in the ski industry. Mitig. Adapt. Strat Glob. Change 12, 1411e1431.

Skjærseth, J.B., Skodvin, T., 2001. Climate change and the oil industry: common problems, different strategies. Glob. Environ. Polit. 1 (4), 43 e64.

Smit, B., Skineer, M.W., 2002. Adaptation options in agriculture to climate change: a typology Mitig. Adapt. Strat. Glob. Change 7, 85e114.

Stern, N., 2008. The economics of climate change. Am. Econ. Rev. Pap. Proc. 98 (2), 1e37.

Sterman, J., 2000. Business Dynamic: Systems Thinking and Modeling for a Complex World. The McGraw-Hill Company.

Tol, R.S.J., 2002. Estimates of the damage costs of climate change. Environ. Resour. Econ. 21, $135 \mathrm{e} 160$.

Wolstenholme, E.F., 2003. Towards the definition and the use of a core set of archetypal structures in system dynamics. Syst. Dyn. Rev. 19 (1), 7 e26.

Yin, R.K., 1994. Case Study Research: Design and Methods, second ed. Sage, Newbury Park, CA. 